\title{
USING CULTURAL PROBES TO EXPLORE MEDIATED INTIMACY
}

\author{
Jesper Kjeldskov ${ }^{1,2}$, Martin R. Gibbs ${ }^{1}$, Frank Vetere ${ }^{1}$, Steve Howard ${ }^{1}$, \\ Sonja Pedell ${ }^{1}$, Karen Mecoles ${ }^{1}$, Marcus Bunyan ${ }^{1,3}$ \\ ${ }^{1}$ The University of Melbourne \\ Australia \\ ${ }^{2}$ Aalborg University \\ Denmark \\ ${ }^{3}$ Charles Sturt University
Australia
}

\begin{abstract}
Intimacy is a crucial element of domestic life that has received insufficient attention from HumanComputer Interaction (HCI) researchers despite their rapidly growing interest in the design of interactive technologies for domestic use. Intimate acts differ from other activities, and there are unexplored opportunities to develop interactive technologies to support these acts. This paper presents the first phase of a two-part study exploring the potential of interactive technologies to support intimate relationships. We contribute to this uncharted domain of HCI research a literature review of concepts useful in understanding intimacy and methods for its investigation. We conclude with preliminary results and suggestive design ideas for interactive technologies intended to support intimacy.
\end{abstract}

\section{Keywords}

Domestic Technology, Personal Technology, Intimacy, Cultural Probes, Contextual Interviews

\section{INTRODUCTION}

Interest in the design of interactive technologies for domestic use has been growing within the Human-Computer Interaction field (Hindus 1999). Recent research has fruitfully examined the instrumental activities involved in coordinating and scheduling family behaviour (Harper 2003), produced rich studies of the multiple meaning attached to domestic routines (Crabtree 2003), performed empirical and technological explorations of fun and leisure (Blythe et al. 2003) and developed proposals for aids to help family members stay in touch (Hofmeer 1999). Inspired by this research, we have been investigating and exploring a crucial element of domestic life that has received relatively scant attention to date from HCI researchers - intimacy. Our research is motivated by a desire to understand how intimate relationships between close family members might be supported by interactive technologies with a view to designing domestic and personal technologies for this very purpose.

Intimate relationships are different from the kinds of relationships that have been typically studied by HCI researchers such as those found in the workplace or amongst social networks of friends. Intimate acts also differ from the domestic behaviours usually addressed in the literature (see Harper 2003 for a review) and attempting to study acts of intimacy presents the researcher with a number of unique and interesting challenges. Studying intimacy is challenging because intimate acts are ephemeral and transient yet ubiquitous and crucial to the ongoing life of an intimate relationship. They form the material and background of close personal relationships, yet occur in the doing and then often vanish unremarked. While the informational content of intimate acts may be low and seemingly trivial to outsiders, the act itself can be laden with emotional significance for those involved. Intimate acts often entail self-disclosure, and thus privacy is a concern. Much of what passes between intimates is unsaid and premised on deep knowledge and understanding of one another and occurs in the context of a rich, shared and sometimes idiosyncratic view of the world that may be difficult for others to fathom and comprehend. Intimacy also involves assumptions about commitment and mutuality, and carries nuanced expectations for reciprocity and exchange that are negotiated and arrived at over many years, yet remain fragile and are occasionally misjudged leading 
to misunderstandings and conflict. Finally, unlike instrumental tasks (e.g. coordination of family activities), or leisure activities (e.g. games) there is no generally accepted language for describing and discussing intimacy, especially in relation to designing technologies for its support.

In this paper we present our response to the interesting issues and challenges arising from our efforts to understand how intimate relationships can be supported with interactive technologies. Our study of 'mediated intimacy' has been divided into two major phases. In the first phase, we have focused on understanding current practice. To this end, we have adopted the 'cultural probes' techniques developed by Gaver et al. (1999) and the Equator team (Cheverst et al. 2003) and extended them with contextual interviews (Beyer and Holtzblatt 1998). We have used these methods to investigate how people appropriate and use the gamut of artefacts, devices and interactive technologies at their disposal to perform the various communicative acts that enable and sustain their intimate relationships. While we have adopted methods that are gaining prominence in the HCI community for investigative work in the domestic environment, how best to explore and understand intimacy remains an open and unexplored question. As a result, the first phase of our study has also had a strong methodological flavour with the aim of developing and refining techniques suitable for investigating these, and similar, phenomenon. The second phase of our study will take the insights and understandings generated in phase one and use them to design interactive technologies to support intimacy. These insights will feed a range of design activities such as the development of use scenarios, participative design workshops, prototype development and evaluation. At the time of writing, the first phase of study has been largely completed and the second phase is about to begin.

In the following section of this paper we present the results of a wide-ranging cross-disciplinary review of the intimacy literature. This review has two parts, the first being a theoretical discussion of the prominent and common themes and concepts found throughout the intimacy research literature. We also consider the use of artefacts to mediate intimacy, with a particular focus on interactive technologies. Mundane artefacts and existing interactive technologies are considered. In addition, a selection of recent prototypes and exploratory interactive technologies that attempt to mediate family relationships are reviewed. We describe in detail our research approach because of its potential for inspiring and informing (Crabtree et al. 2003) the design of interactive domestic technologies. We then present preliminary results from the first phase of our study of current practice, highlighting the key analytic themes that have emerged from our investigation of how interactive technologies are used within intimate relationships. Based on these finding, we offer three, broad-brush and indicative suggestions for the design of interactive technologies to support intimacy.

\section{WHAT IS INTIMACY?}

Although there are many interesting discussions and perspectives, there are no agreed-upon definitions of intimacy (Register and Henley 1992, Moss and Schwebel 1993, Robson and Robson 1998). In this section, we discuss what constitutes intimacy. We believe a clearer understanding of intimacy is important because it provides a basis for the design of artefacts that better support intimate relationships. With the purpose of understanding intimacy and its contributing factors, we conducted a literature review of conference papers, journal papers and book chapters. This section extracts some of the major themes from this review.

According to Cheal (1987), an intimate relationship consists of a private world of significant others, which needs to be continuously maintained. In intimate relationships the significant other is often reminded that "they are indeed significant". People remind each other through gestures, actions and gifts, some of which may be routine and unremarkable. Our study provides an opportunity to investigate these exchanges of intimacy. The literature provides a framework or 'lens' for conducting the observation. 
While the literature provides no unanimous agreement about what constitutes intimacy, some common themes do appear. Our review offers eight prominent aspects of intimacy. These are: physical intimacy, non-verbal communication, self-disclosure, presence, cognitive intimacy, affective intimacy, commitment and mutuality.

Physical intimacy plays a central role in people's description of their own intimate behaviour (Robson and Robson 1998) and is acknowledged as an essential aspect of intimate relationships (Register and Henley 1992; Battarbee et al. 2002). Physical intimacy is the sharing of physical encounters ranging from close physical proximity to sexual contact (Moss and Schwebel 1993). Physical intimacy is not only concerned with bodily contact. Physical intimacy also includes the visceral experience of heightened awareness of ones own body or feelings of new bodily experiences (e.g. butterflies in the stomach, weak at the knees), arising from physical or mediated contact with another (Register and Henley 1992).

Non-verbal communication is identified by several researchers as a significant carrier of personal expression in intimate relationships. Non-verbal communication is communication by means of actions, gestures, facial mannerisms, close physical proximity or touch (Register and Henley 1992, Battarbee et al. 2002). Non-verbal communication is the aspect of intimacy that is better expressed through sensory evocations rather than linguistic forms, and helps to avoid the confusion that is sometimes caused by words (Register and Henley 1992).

Self-disclosure is a key characteristic that often differentiates intimate from non-intimate relationships (Register and Henley 1992, Moss and Schwebel 1993, Robson and Robson 1998). Selfdisclosure is the act of revealing private information, such as the personal feelings of one person toward another. Self-disclosure includes the removal of boundary between oneself and an intimate other (physically and psychologically), getting inside the life of another, and/or allowing another to cross one's personal boundary (Register and Henley 1992). Self disclosure demands a certain degree of trust in the other and making oneself vulnerable. Furthermore, disclosing personal details often leads to an increased level of self-disclosure from an intimate other (Duck 1988). Thus, selfdisclosure is an effective mechanism for maintaining and changing the level of intimacy in a relationship. Disclosing too little or too much can either escalate or de-escalate a relationship (Robson and Robson 1998).

Presence is the subjective feeling of another person being present in either a physical and/or a nonphysical manner (Register and Henley 1992). The feeling of presence can be triggered by symbolic actions of the absent one(s) or the feelings can emerge spontaneously without any (objective) external cause. Thus, while being very powerful and contributing strongly to the feeling of intimacy with another, the feeling of another person being present in absence is very complex, subjective, and sometimes highly irrational. A feeling of presence is not so much due to being physically co-located, but due to re-living the pleasure related to being in the company of another person (Register and Henley 1992). Complementing this view, other researchers note that presence goes both ways. They stress the importance of feeling oneself being present to another (in either a physical or a nonphysical manner) for creating and maintaining intimacy (IJsselsteijn et al. 2003, Biocca and Harms 2002).

Cognitive intimacy reflects the depth of awareness and knowledge intimates have of one another (Moss and Schwebel 1993). Cognitive intimacy is characterised by feelings of 'knowing' the other. Intimate friends, dating partners and spouses typically develop deep cognitive understandings of each other, and often share a range of personal information and preferences. This includes knowing 
one another's principles, values, strengths, weaknesses, hopes, fears and idiosyncrasies (Altman and Taylor 1973). Also, it has been shown that increasing the amount of cognitively exchanged information between spouses increases the level of intimacy they experienced. Thus being able to establish and maintain a shared cognitive life is a major requirement for building and sustaining an intimate relationship.

Affective intimacy is the reception and expression of emotion (Moss and Schwebel 1993). Affective intimacy involves a feeling characterized by a deep sense of love, caring, compassion and positive attraction for one another. Affective intimacy reflects the depth of awareness intimates have of one another's emotional world and the emotional exchanges they share. The level of affective closeness in friendships, serious dating relationships or marriage, is commonly reported as closely related to the level of intimacy of that relationship (Levinger and Senn 1967). Also, affective intimacy is often highlighted as a key differentiator between close friendships and relationships involving romantic love (Moss and Schwebel 1993).

Commitment is the extent to which partners in a relationship perceive their relationship as ongoing for an indefinite period (Chelune et al. 1984). Commitment includes acts intended to grow or maintain intimacy. Being in a committed relationship generates strong feelings of cohesion and connection (Moss and Schwebel 1993). Commitment is an important foundation for intimate relationships and often a precondition for other aspects of intimacy (e.g. self-disclosure) to flourish (Chelune et al. 1984). Misunderstandings in the expression of commitment and changes in one partner's belief in the commitment of the other may impede the growth of an intimate relationship or initiate its decline (Chelune et al. 1984, Duck 1981). Thus, being able to convey and experience commitment constitutes a crucial requirement for building and sustaining an intimate relationship.

Mutuality is considered the centre of any intimate relationship (Cheal 1987, Chelune et al. 1984). Mutuality is the assumption that intimate partners are co-engaged in a common cause. Mutuality originates from a process of exchange, interdependence and reciprocal expectations (Moss and Schwebel 1993). Mutuality exists when gifts or symbolic signs of value are exchanged (Cheal 1987). Mutuality is characterized by a sense of fairness shared by both partners in relation to the rewards and costs of their interactions (Chelune et al. 1984). While mutuality implies joint and shared interactions, it does not necessarily require similar or identical patterns of interaction. Rather, intimate relationships may involve both reciprocal interactions (partners showing similar behaviour) and complementary interactions (partners showing different behaviour that complements each other). We believe these eight aspects of intimacy are useful for understanding how intimacy is constituted. However, it is important to note that these components do not exist or work independently, nor do they individually satisfy the intimate experience. Indeed, the themes overlap greatly and are highly interrelated (Moss and Schwebel 1993). The themes discussed above suggest that intimacy includes both a behavioural and an emotional level involving, on one side, actions caused by or causing a feeling of intimacy (such as mutuality, self-disclosure, non-verbal communication or physical intimacy) and, on the other side, feelings of intimacy (such as affective intimacy, cognitive intimacy, presence or commitment) caused by or causing these actions. Thus if technology is to support the mediation of an intimate relationship, it needs to facilitate these behaviours and emotions.

\section{MEDIATED INTIMACY}

People have always used artefacts to mediate their intimate relationships. Intimacy has been mediated through symbols of affection such as flowers and rings, through public declarations of love scrawled on park benches, through secret notes and love letters, and more recently through text messages on mobile phones. These ways of mediating close relationships share various combinations 
of our eight characteristics of intimacy. Flowers are nonverbal, they express emotion (affective intimacy) and they often symbolise gratitude (mutuality). Written letters afford self-disclosure, knowledge of personal secrets (cognitive intimacy) and commitment. When one partner returns to the park bench alone, the scratching is a reminder of their absent loved one (presence).

It is not surprising then that some recent technologies have been quickly appropriated and added to the repertoire of artefacts for mediating intimacy. Notably, the Internet is used for matchmaking and exploring options for personal relationships (Donn and Sherman 2002). Furthermore, SMS (Short Message Service) is increasingly used to forge new romantic relationships (Byrne and Findlay 2004), to coordinate activities with intimate friends (Grinter and Eldrige 2001) and to use text messages as gifts between close others (Taylor and Harper 2003).

There are also an increasing number of prototypes and exploratory technologies that attempt to mediate close relationships between couples and family members. Some of these support the often stated need to simply keep-in-touch. Rather than using 'intense' technologies (such as telephones), researchers are exploring uni-modal technologies (such as a light or movement) and evocative materials to create a feeling of presence-at-a distance. These technologies generate a sense of presence by exploiting peripheral awareness (Gaver 2002) and a prior understanding of routines. For example: a feather in a plastic cone floats when the distant partner picks up a picture frame of the couple (Gaver 2002); a light 'orb' glows in Australia when a family member in London walks into their apartment (Tollmar and Joakim 2002), a special bowl ('Gustbowl') wobbles when an adult son living away from his parent's house, arrives home and places his keys in a similar bowl (van der Hoog et al. 2004). The wobble, signifying "I'm home", reassures the concerned parents.

Traditionally, physical intimacy could only be achieved through physical contact. Until recently, mediating physical intimacy over long distance was not technologically possible. However new technologies are exploring notions of telepresence to bridge the barrier of physical distance. For example: two sets of cylinders that roll and rotate in unison as they are manipulated by separated partners (Brave and Dahley 1997); wearable tokens that transmit touch directly as pressure (Hindus et al. 2001) or through vibration (Chang et al. 2002); a bed that senses body position and transmits warmth to congruent parts of a lovers bed (Goodman and Misilim 2003). These devices not only mediate physical intimacy, they also support mutuality; i.e. the interplay or reciprocity of exchanges. These exchanges need not be symmetrical. For example 'Satellites' (Battarbee et al. 2002) consists of two 'huggable' balls. One ball captures video and emits sound while the other captures sound and emits video. The asymmetric modalities provoke playful and creative communication. This mutuality, or sense of 'other' is generated through negotiating the constraints of the technology.

\section{PROBING INTIMACY}

This paper addresses the challenge of investigating intimacy and designing interactive technologies to support intimate acts. Our approach is a combination of ethnographic techniques and participatory design approaches that allow us to collaborative explore the phenomenon with a small group of 'participant-research' subjects. To this end we have adopted the 'cultural probes' techniques developed by Gaver et al. (1999) and the Equator team (Cheverst et al. 2003) and extended them with contextual interviews (Beyer and Holtzblatt 1998). Cultural probes are a novel collection of techniques gaining prominence in interactive systems design. They are particularly suited to investigating people's everyday life in situations difficult to reach with traditional social science methods such as questionnaires, interviews, focus groups or participant-observation. Probes are designed to prompt and elicit information from people about their lives and 'local culture' (Gaver et al. 1999). In particular, probes are designed to garner an understanding of the playful character of human life and the multifaceted ways people 'explore, wonder, love, worship, and waste time' (Gaver 2001). Cultural probes gather insight from within the site in question, with the full 
cooperation and involvement of the participants concerned. The insights are gathered as activities are performed and while technology is in use, thus maintaining 'fidelity to the phenomenon' under investigation (Crabtree et al. 2003).

Like deep sea or planetary probes, cultural probes are 'sent-out' by researchers and return fragmentary data over time. Rather than relying on the presence and intervention of the researcher, cultural probes are designed to encourage and empower subjects to collect data themselves (Arnold 2004). This allows the collection of data from situations where researcher presence is problematic by giving participants the means to record everyday activities as they occur or shortly afterwards. It also allows research materials to be collected over longer periods in multiple locations compared with resource intensive methods such as traditional ethnographic approaches.

\section{Cultural Probes}

We assembled a collection of cultural probes into a 'probe pack' (figure 1). The probe pack contained:

- Two scrapbooks providing the participants with an open format for creative and rich descriptions of both current practice and imagined future technologies

- Two diaries (one for each partner) allowing the participants to individually describe the temporal flow and routine of their lives throughout the period of study

- A digital camera and a photo printer allowing the participants to capture, print, edit and annotate up to 180 photographs for the scrapbooks, diaries and postcards

- Catchphrases (e.g. "I feel lonely when..." or "I really love it when...") printed onto sticky labels allowing the participants to stick them into the diaries or scrapbooks provoking reflection by the participants

- Various consumables including stamped pre-addressed postcards, coloured Post-It notes, pens, crayons, paper clips, glue and scissors etc. for use with the scrapbooks.

- Information for contacting the researchers via landline, voice-mail, e-mail and SMS throughout the study.

Probe packs were given to six couples. Participants were asked to use the probes to articulate the role technology played in their relationship. Probes were used to elicit: where, when, how and why they interacted; how they felt during interaction; and reflections on the usefulness of current technologies in these situations.

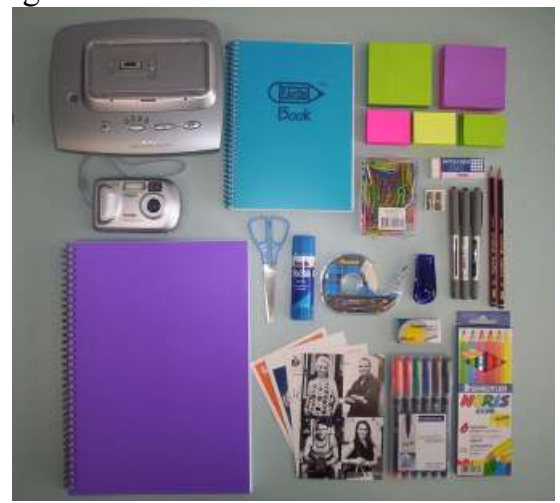

Figure 1: Contents of the probe pack

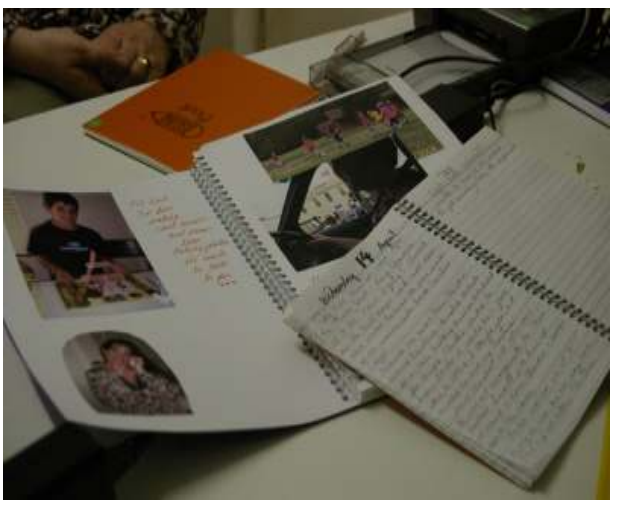

Figure 2: Scrapbook and diary from participants

AJIS Special Issue

December 2004 
The diaries were used individually to record daily communication and interaction activities. This included the form of communication (e.g. SMS) and other details such as time, date, location, the content and the feelings associated with it (e.g. urgency or dissatisfaction). The scrapbooks were used collaboratively to tell rich and evocative stories about communicative events and to express the technology wants, desires, likes and dislikes surrounding these events. Couples were encouraged to use coloured notes, pens, crayons, glue, photos, magazines clippings, drawings and so forth to form a montage of their intimate lives. The digital camera and printer were used to photograph and print significant events. The docking printer provided the immediacy of traditional Polaroid photographs with the convenience of lasting digital images. Participants were encouraged to take photographs of everyday artefacts or events that express some important dimension of their interactions: the answering machine at the time of receiving some unexpected news or of a child in a football final to share with an absent parent. Participants were asked to print, to annotate and to cut and paste the photographs into their scrapbooks or diaries or postcard, as they saw fit (figure 2). Finally, the participants were asked to read and reflect on the catchphrase labels, complete them, and stick them into the diary, scrapbook or on a post card. The stamped postcards could be used for short stories or images to be sent to the researchers or intimate other.

It was stressed that nothing in the probe pack was compulsory. The instructions were only suggestions. All the materials could be used in whatever way they wished. No time requirements were made, but it was suggested that the participants should spend about 20-30 minutes each day using the probe pack materials.

An additional probe element was introduced midway through the study. This new element consisted of small printed facsimiles of a variety of mobile device screens (e.g. mobile phones and personal digital assistants). This new element served to both refresh participants engagement in the study and encourage them to envision possibilities for future technologies to support their relationship. Participants were invited to use these mobile device screen facsimiles to note design ideas and to insert them into the scrapbooks or diaries (see figure 4).

\section{Contextual Interviews}

Our study combined cultural probes with a series of contextual interviews (figure 3 ). These interviews gave participants the opportunity to explain, clarify and expand upon the materials they had collected and collated through their work with the culture probes. In these interviews, the probes became a starting point for a conversation between researchers and participants that revolved around the participant's relationship, and the roles played by technologies in mediating (or not) their intimacy. The probes recorded fragments that were used during interviews to prompt memory, seek explanation, and encourage reflection. Through these interviews we were able to uncover previously unarticulated aspects of their relationship and intimate behaviours, routines and habits. Participants and researchers worked together to develop a shared understanding of how the relationship 'worked' and the roles technologies played and didn't play in mediating their engagement with each other. Interviews also allowed regular contact between researchers and participants. These meetings were used to 'tune' participant's engagement with the probe materials. Meetings were used to check on participants understanding of the study, to gently steer them toward the intended focus of the study, to ask them to focus more on certain probe activities and to introduce additional tasks. Returning from these interviews, researchers brought back a wealth of data that fuelled ongoing discussion, reflection and analysis by the research team. 


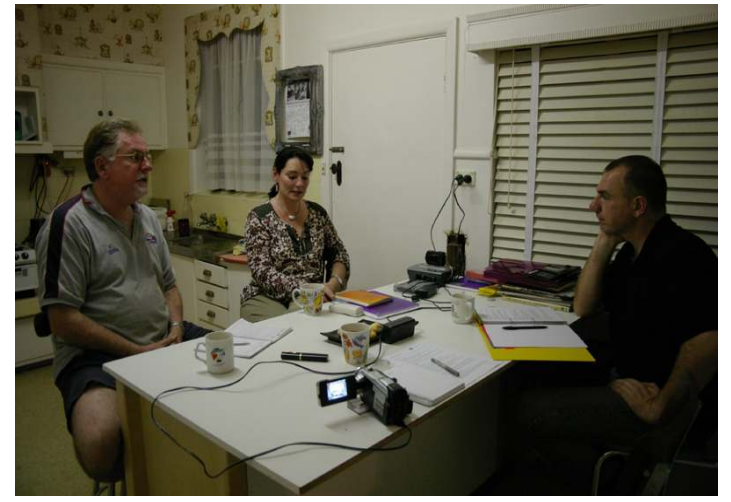

Figure 3: Contextual interview with participants

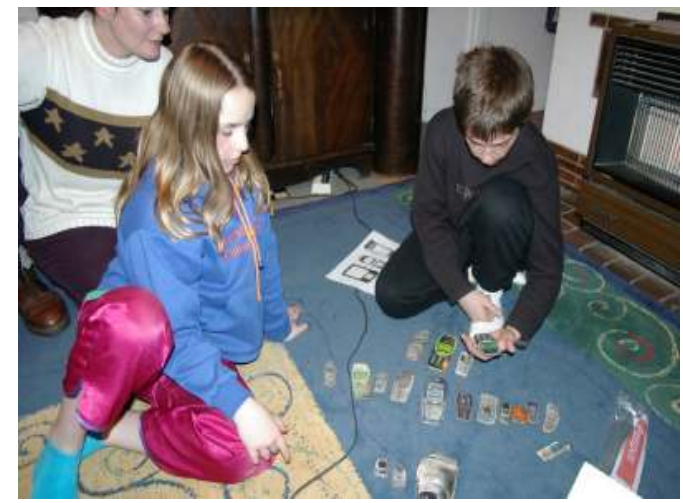

Figure 4: Participant's children playing with facsimiles

\section{Participants}

The study involved six mixed-gender couples in long-term, stable relationships. All couples cohabitated, although work related travel occasionally required periods of separation. The age of participants ranged from late 20's to late 40's. Three couples had children, ranging in age from 18 months to 12 years of age. All couples used a variety of electronic media such as landline and mobile telephony, email, chat, SMS and fax to communicate with each other, although the exact mix of technologies used by each couple varied markedly.

\section{Procedure}

The couples were recruited through a screening process involving an initial, informal interview. Couples were selected to give diversity in both family situation (no children, very young children, older children); the degree to which they used ICTs to communicate with one another (once or twice a day up to 20 or more times a day); and types of technologies they used. Important in the selection of participants was the degree to which participants were willing and able to articulate, discuss and reflect on their relationship as well as their ability to engage in imaginative speculation about future ICTs. Two researchers were assigned to each couple and were responsible for introducing the cultural probe pack and conducting all contextual interviews with the couple. Interviews were predominantly conducted in the participants' homes, but some interviews were conducted at the University and several were conducted in a café. Choice of interview location was at the discretion of participants.

The cultural probes were deployed for a period of seven weeks. At the beginning of this period, an initial interview was carried out at the participant's homes. This included questions about the participants' backgrounds, their relationship, their communication habits and their use of technology. Following the interview, the researchers presented the cultural probe materials and instructed the participants on how to use them. After the first week of the study, the researchers visited the participants' homes again for a second interview. The purpose of this visit was to ensure the participants were 'on track' with the use of the probes and to investigate the activities of the first week through a conversation about the data collected in the diaries and scrapbooks.

Following the second interview, participants were left to work with the probe pack for three weeks, at which time, a third interview was conducted. The purpose of the third interview was to examine and review the materials collected through the probes since the last interview. Researchers and 
participants discussed the materials accumulated in the scrapbooks and diaries, and participants were invited and encouraged to clarify, elaborate and reflect on the materials they had recorded and composed over the previous three weeks. At the end of the third interview session, researchers introduced the small printed facsimiles of mobile device screens. Participants annotated these facsimiles to explore novel designs in situations where current technology inadequately supports personal communication and interaction (figure 4). After the third interview, the participants were again left to work with their probe materials for three weeks. In the fourth and final interview, researchers discussed the diaries, scrapbook and other materials composed over the previous three weeks. In addition, researchers and participants discussed design ideas produced on the mobile device screen facsimiles. This interview was also used to bring closure to the seven-week process. The researchers retrieved all materials gathered through the cultural probes at this time. It is our intention to return the probe pack diaries and scrapbooks to participants as a 'gift' after our analysis of the material is completed (copies will be retained for our records).

\section{RESULTS}

The contents of the scrapbooks, diaries and interviews were reviewed and discussed on a weekly basis by the research team. On the basis of our analysis of material collected in the first four weeks of the study, we present some preliminary findings.

A theme occurring across all couples was a strong need to support presence in absence. This is a feeling that the other is present, even though they may be far away. This is closely related to the issue of presence discussed earlier. Participants identified a desire to be in contact with each other while physically separated. This does not only happen when one partner is away for a long period of time, it also occurs during ordinary workdays, sometimes with only minutes separation. For example, couples who work in office buildings a few blocks apart or couples who work on different floors of the same building are in regular contact, up to 10 times a day, via phone, SMS, or email. Often the messages play the dual role of organising family affairs (e.g. "Who is picking up the children?" or "What is planned for dinner tonight?") and for declaring a caring presence ("I am here, thinking of you"). Other examples of creating presence-in-absence are through indirect, non-verbal communication "by proxy", for example, one partner preparing breakfast for the other before leaving for work. Presence is not only created by exchanges of message. Artefacts themselves carry presence. Merely carrying a mobile phone, because it affords the opportunity for immediate contact if desired, creates a sense of presence and feelings of security and comfort. Furthermore, absence need not be physical. In some instances, couples who were physically nearby but engaged in separate activities supported presence-in-absence by communicating with each other using SMS from the lounge room to the bed room or email from one side of the room to the other. In these examples, physical presence did not compensate for emotional absence. The couples felt a desire to be more present than afforded by physical closeness. This desire was mediated by technology.

Our study suggests that much of the communication that passes between intimates is emotional rather than factual. While intimate communication is not 'fact free' it often plays a role more akin to 'stroking and patting' than verbal conversation. The messages are often information poor, but laden with significance. Examples include spontaneous gift giving, messages of affection, flirtation, telephone calls to chat about nothing in particular. Many of these interactions serve to confirm that a person is thinking about, caring for and aware of their partner. It is often the act itself, rather than the explicit message it carries, that is significant.

Intimate acts are often ambiguous and incomplete, suggesting and hinting rather than explicating in detail. They occur in the context of a rich, shared and sometimes idiosyncratic view of the world. This shared world view is vital to feelings of intimacy and is also a resource artfully drawn on by intimates during interaction. 
It comes as no surprise that our study indicates that intimate acts are often private. Our results suggest privacy has many dimensions. For example, intimacy entails self-disclosure. Intimates reveal something of themselves to each other and they may feel vulnerable if their interactions are exposed to the gaze of outsiders. As a result, intimate acts are often constructed to be hidden from the view of others. Participants in our study were selective in the communication media they choose for interaction, and partly based these decisions on their perception of the privacy and security of the various communication channels at their disposal. For example, some did not use work-based email for certain intimate exchanges because they were aware that system administrators can view their emails. Similarly, intimate information was not disclosed while on a crowded but quiet train car or over the telephone in an open plan office. Some participants, particularly those who regularly used workplace technologies to communicate with each other, reported taking efforts to obscure that they were engaged in communication with their partner.

Even when intimacy is displayed in public, these acts can be nuanced and imbued with private meaning difficult to see and interpret by outsiders. Some participants developed private 'codes' and short-hands to communicate with one another, such as an SMS of '146' for 'I love you' or calling the home telephone and allowing it to ring thrice at certain times of the day to signify 'I'm awake, I'm OK, I'm thinking of you'. Others engaged in flirting in situations were flirting was inappropriate such as knowingly sending provocative SMS messages when their partner was in a work meeting relying on the personal form of these messages to obscure their lack of proprietary. Some participants reported drawing on their shared past and detailed knowledge of one another to privately communicate in the full view of others, using oblique references that were presumably ambiguous or meaningless to others, such as when one end of a telephone conversation could be overheard. More generally, participants often drew on a repository of anecdotes, past conversations, knowledge of events and running jokes in their interactions. Indeed, much of what passes between intimates is unsaid and premised on deep knowledge and understanding of one another.

Actively constructing and maintaining a shared history was also important to participants. All participants collected mementos, photographs and other materials that evoked their past together. Some participants invested significant effort in constructing and maintaining these records in scrapbooks and photo albums, and often collaborated in reviewing and updating these repositories. These mementos were at once a public declaration of ongoing commitment and artefacts through which past intimate feeling could be rekindled. With the advent of digital photography, some participants had begun keeping digital archives of photographs burnt to CD-ROM for viewing and reviewing on the home DVD player, often as a joint activity.

Participants were also engaged in a common journey and shared the costs and rewards of lives together. Where a shared history brought comfort from the past, a common journey generates hope for the future. Both are related to the theme of commitment. Features of the participants' lives, such as raising children, caring for older family members, maintaining the household, or travelling to work, were all enterprises that were shared and, in the sharing, became vehicles for enacting, affirming and maintaining their relationship. Joint responsibility was taken for domestic life, including activities such as paying the bills, transporting children and preparing meals. These activities were often coordinated on the fly using interactive technology such as mobile phones. The division of labour within these relationships had regular patterns but was also fluid and renegotiated over the course of a day. In addition, responsibilities also provided occasions for affirming the relationship. For example, the success of a child at school was affirming "our" achievement as "good parents". Even activities that were the sole responsibility of one member of the relationship became joint enterprises. Participants reported drawing on their partner's help and skills for work related tasks such as database development, setting up a web-based email account or writing a job 
application. Being able to help and share common tasks affirmed the relationship and sense of moving through the world together as a team, rather than as atomised individuals.

Above all, our participants reported the need to find time to be alone together away from the hectic schedules of family and work related responsibilities that dominated their lives. Whether this time alone was found while driving a car with the children asleep, sharing a meal at the end of the day, or even working on separate projects but sharing the same physical space to do so, all felt that physical closeness was crucial to their relationship, and something that could not be adequately replaced or mediated by interactive technology.

All our intimate relationships involve expectations and assumptions about reciprocity and exchange between partners. In our study, we found interaction was founded on a commitment from both parties to reciprocate in both content and form. These expectations were nuanced, negotiated and arrived at over many years, yet remain fragile and are occasionally misjudged and misinterpreted leading to misunderstandings and conflict.

Our study has also taught us that it is important not to romanticise intimacy. Intimacy and the tight, emotionally charged bonds it entails, is fragile. While relationships may be robust, misunderstanding, and misinterpretations do occur. When they occur, these breakdowns can have serious repercussions; creating ill will and emotional hurt that can obstruct and undermine intimacy within the relationship. The fallout from a simple breakdown in understanding between partners can reverberate through the relationship for days, if not weeks. For these reasons, any interactive technology designed to support or mediate intimacy needs to mitigate against these forms of breakdown and allow for easy and rapid repair of them when they do occur.

Even though our results are still preliminary, they have given us a deeper understanding of how some of the themes identified in the literature contribute to intimacy, and how people use technologies to support and sustain them. Our challenge is to translate our observations and extended knowledge of the central themes to designs.

\section{DESIGN IDEAS}

We now present three preliminary design ideas that have been distilled from the data. The designs are intended to exploit opportunities for technologically mediating intimacy. The designs are not necessarily futuristic. Similar designs may already exist. It is not our intention to implement these design ideas in their current forms. Rather we intend to use the design ideas to seed ongoing design activities such as participant design workshops and scenario-based acting out (Howard et al. 2002).

Memorabilia Manager: Couples spend a great deal of time and energy organising their personal mementos. These are typically photographs and videos, but often include other items such as tickets (e.g. airline ticket from a honeymoon) and souvenirs (a sea shell from that special holiday). These have important value for intimate relationships. They signify common history and a shared journey and contribute to the broad theme of commitment. A 'Memorabilia Manager' should be very portable and allow the experience of creating and reviewing the memorabilia. It would allow couples to compose digital and non-digital forms into a meaningful mosaic. It would be a type of 'family blog' that facilitates simple recording of family events.

Constant Touch: Face-to-face communication was regarded by all participants as an authentic experience, while mediated interaction as somewhat impoverished, thin and 'abstracted'. However, when face-to-face interaction was not possible (or practical) intimates desired connectedness and presence. 'Constant Touch' is akin to walkie-talkie or 'push-to-talk' devices (Telstra 2004). It provides an open channel for constant updating throughout the day. It may contain a single point transducer (such as a light) that is activated when one wants to say "I'm thinking of you". The form is configurable to suggest a physical presence as if "She is with me all the time". 
Family Digital Assistant: If a family had children, then the children tended to dominate all activities - including intimate ones. Children were an anchor to the family's life and a key mediator for the expression of intimacy. Rather than finding intimacy beyond family duties, it was through the routine of child-raising that intimacy was expressed. The 'Family Digital Assistant' (FDA) acknowledges that shared mundane experiences are part of the intimate experience. Where a PDA is for personal purposes, a FDA coordinates family activities. We observed that poor coordination can lead to emotional hurt and bad tempers. The FDA is a response to this need.

\section{CONCLUSIONS}

Intimate relationships involve an intricate and nuanced dance between partners involving a complex array of varied activities. Many of these take place in close physical proximity and involve touch and face-to-face communication. Others are mediated across space and time and involve activities such as talking on the phone or writing letters and postcards. While mediating intimacy is not a new phenomenon, new technologies influence how, when and why we interact with each other. However, little is known about the adoption and use of these technologies within intimate relationships and even less is known about how, when and why they provide good support for mediating intimacy and how, when and why they fail.

Perhaps more than the majority of domestic acts, intimacies display fragility when under examination. In this paper we have described an approach to the study of intimacy that stressed the need to empower participants; providing them with means to record intimacies during or soon after the acts themselves and means to describe intimacy in their own words. We have stressed the importance of hearing the 'voice of the intimates' given our current lack of understanding of this new domain of HCI. Although we have largely limited our report of our preliminary findings to the analysis and description of current practice, our approach has also aimed to be playful; we have worked to encourage and legitimise participants' exploration of possible futures, rather than strictly limiting them to reporting on their current practice. The insights generated through this playful imagining will be the topic of subsequent work.

\section{REFERENCES}

Altman, I. and Taylor, D.A. (1973) Social Penetration: The development of interpersonal relationships. Holt, New York.

Arnold, M. (forthcoming 2004) The Connected Home: Probing the Effects and Affects of Domesticated ICTs, Proceedings of PDC2004, Toronto, July 27-31 2004, ACM.

ASTRA Project (2004) http://www.presence-research.org/Astra/ (Accessed May $7^{\text {th }}$ 2004)

Battarbee, K., Baerten, N. and Loeber, S. (2002) Pools and Satellites - Intimacy in the City. Proceedings of DIS 2002, ACM, 237-245.

Beyer, H. and Holtzblatt, K. (1998) Contextual Design: Defining Customer-Centered Systems, Morgan Kaufmann, San Francisco.

Brave, S. and Dahley, A. (1997) inTouch: a medium for haptic interpersonal communication. Extended Abstracts from CHI'97, Atlanta, GA, USA, ACM.

Byrne, R. and Findlay, B. (2004) Preference for SMS versus Telephone Calls in Initiating Romantic Relationships. Australian Journal of Emerging Technologies and Society (Issue 2: Autumn 2004)

Biocca, F. and Harms, C. (2002) Defining and Measuring Social Presence: Contribution to the Networked Minds Theory and Measure. Proceedings of Presence 2002, ACM. 
Chang, A., O’Modhrain, S., Jacob, R., Gunther, E. and Ishii, H. (2002) ComTouch: Design of a Vibrotactile Communication Device. Proceedings of DIS 2002, London, England, ACM.

Cheal, D. (1987) 'Showing them you love them': Gift giving and the dialectic of intimacy. The sociological Review, 35(1):150-169.

Chelune, G.J., Robison, J.T. and Kommor, M.J. (1984) A Cognitive Interactional Model of Intimate Relationships. In Derlega, V.J. (ed.) (1984) Communication, Intimacy, and Close Relationships. Academic Press, Inc., New York.

Cheverst, K., Clarke, K., Dewsbury, G., Hemmings, T., Kember, S., Rodden, T. and Rouncefield, M. (2003) Designing Assistive Technologies for Medication Regimes in Care Settings. International Journal of Universal Access in the Information Society (UAIS), 2003.

Crabtree, A., Hemmings, T., Rodden, T., Cheverst, K., Clarke, K., Dewsbury, G., Hughes, J. and Rouncefield, M. (2003) Designing with Care: Adapting Cultural Probes to Inform Design in Sensitive Settings. Proceedings of OzCHI 2003, Brisbane, Australia.

Crabtree, A. (2003) Remarks on the Social Organisation of Space and Place. Homo Oeconomicus, XIX(4), 591-605.

Donn, J.E. and Sherman, R.C. (2002) Attitudes and Practices Regarding the Formation of Romantic Relationships on the Internet. CyberPsychology \& Behavior, 5(2), 107-123.

Duck, S. (1988) Relating to Others. Open University Press, London.

Gaver, B. (2002) Provocative Awareness. Computer Supported Cooperative Work, 11: 475-493.

Gaver, B. (2001) Designing for Ludic aspects of Everyday Life, ERCIM News, 47. http://www.ercim.org/publication/Ercim_News/enw47/gaver.html, Accessed 16 June 2004.

Gaver, B., Dunne, T. and Pacenti, E. (1999) Design: Cultural Probes. Interactions, 6(1), 21-29.

Goodman, E. and Misilim, M. (2003) The Sensing Bed. Proceedings of UbiComp 2003, Seattle Washington.

Grinter, R.E. and Eldrige, M.A. (2001) Y Do Tngrs Luv 2 Txt Msg? Proceedings of the Seventh European Conference on Computer-Supported Cooperative Work, ECSCW '01, Bonn, Germany.

Harper, R. (ed.) (2003) Inside the Smart Home. Springer-Verlag, London.

Hindus, D., Mainwaring, S., Leduc, N., Hagstrom, A., and Bayley, O. (2001) Casablanca: Designing Social Communication Devices for the Home. Proceedings of CHI 2001, ACM.

Hindus, D. (1999) The Importance of Homes in Technology Research. Proceedings of the Second International Workshop on Cooperative Buildings (CoBuild'99), Pittsburgh USA, Springer-Verlag.

Hofmeer, K. (1999) The Digital Hug: Keeping Families Together. Interactions, 6(6).

Howard, S., Carroll Jennie, Vetere, F., Murphy, J. and Peck, J. (2002) Provoking Innovation: Acting out with contextual scenarios. Proceedings of BCS-HCI 2002, Springer-Verlag, London.

IJsselsteijn, W., van Baren, J. and van Lanen, F. (2003) Staying in Touch - Social Presence and Connectedness through Synchronous and Asynchronous Communication Media. Proceedings of the 10th International Conference on Human-Computer Interaction 2003, Crete, Greece, Lawrence Erlbaum Associates.

Levinger, G. and Senn, D.J. (1967) Disclosure of feelings in marriage. Merill-Palmer Quarterly, 13, 237-249.

Blythe, M.A., Overbeeke, C.J., Monk, A.F., and Wright, P.C. (Eds) (2003) Funology: From Usability to Enjoyment. Kluwer, Dordrecht.

Moss, B.F. and Schwebel, A.I (1993) Marriage and Romantic Relationships: Defining Intimacy in Romantic Relationships. Family Relations, 42(1): 31-37.

Register, L. and Henley, T. (192) The Phenomenology of Intimacy. Journal of Social and Personal Relationships, 9, 467-481. 
Robson, D. and Robson, M. (1998) Intimacy and Computer Communication. British Journal of Guidance and Counselling, 26(1):33-42.

Taylor, A., and Harper, R. (2003) The Gift of the Gab?: A Design Oriented Sociology of Young People's Use of Mobiles. Computer Supported Cooperative Work, 12(3): 267-296.

Telstra (2004) What's Doing: Telstra completes Push To Talk trial with services to be available in June http://telstra.com/countrywide/Peninsula/localtelstra.asp?page=whatsdoing, Accessed 15 June 2004.

Tollmar, K., and Joakim, P. (2002) Understanding Remote Presence. Proceedings of NordiCHI 2002, Aarhus, Denmark, ACM.

van der Hoog, W., Keller, I., and Stappers, P.J. (2004) Gustbowl: Technology Supporting Affective Communication through Routine Ritual Interactions. Proceedings of CHI 2004, Vienna, Austria, ACM.

\section{ACKNOWLEDGEMENTS}

The authors would like to thank all couples participating in the study and acknowledge the support of the Smart Internet CRC and the Danish Technical Research Council (project reference 26-03-0341).

\section{COPYRIGHT}

Jesper Kjeldskov, Martin R. Gibbs, Frank Vetere, Steve Howard, Sonja Pedell, Karen Mecoles, Marcus Bunyan (C) 2004. The authors assign to OZCHI and educational and non-profit institutions a non-exclusive licence to use this document for personal use and in courses of instruction provided that the article is used in full and this copyright statement is reproduced. The authors also grant a non-exclusive licence to OZCHI to publish this document in full in the Conference Papers and Proceedings. Those documents may be published on the World Wide Web, CD-ROM, in printed form, and on mirror sites on the World Wide Web. Any other usage is prohibited without the express permission of the authors. 